\title{
ASSISTENCIA DE ENFERMAGEM A PACIENTE DEPENDENTE DE DROGAS
}

\author{
Maguida Costa Stefanelli* \\ Ilza Marlene Kuae Fukuda* \\ Evalda Cançado Arantes**
}

STEFANELli, M. C.; FUKUDA, I. M. K.; ARANTES, E. C. Assistência de enfermagem a paciente dependente de drogas. Rev. Esc. Enf. USP, São Paulo, 13(2): 127-134, 1979.

As autoras apresentam algumas noções búsicas sobre a dependência de drogas, o comportamento do paciente farmacodependente e a assistência de enfermagem a ele prestada. Abordam, também, alguns aspectos profiláticos da farmacodependência.

\section{INTRODUÇÃO}

O uso abusivo de drogas que causam dependência é um problema crescente, principalmente entre os jovens, e de âmbito internacional. Diversos autores abordam o assunto. OLIVNSTEIN ${ }^{8}$ relata que os adultos ficam chocados ao perceber o uso que seus filhos fazem de produtos fármaco-químico que alteram a concepção da existência. VIDAL et alii ${ }^{11}$ fazem referência ao aumento da farmacodependência entre os jovens. EY et alii ${ }^{1}$ citam o aumento de farmacodependência entre os jovens como fenômeno de massa na América e na Europa. GREENBLATT \& SHADER ${ }^{3}$ consideram um problema aflitivo o aumento da dependência de drogas entre os jovens. WARNER ${ }^{12}$ afirma que a farmacodependência está se tornando um problema epidêmico na Europa atual.

O homem, muitas vezes, envolve-se com drogas que causam dependência, movido pela curiosidade ou numa tentativa de se libretar de uma ansiedade crescente, na esperança de conhecer um mundo melhor ou diferente. Outras vezes, são os intermediários ou traficantes de drogas que levam o homem ao consumo das mesmas.

0 estudo sobre o efeito de uma droga torna-se cada vez mais complexo uma vez que é raro encontrar-se pessoa que utilize um único tipo de droga. $O$ comum é o uso de várias drogas - politoxicomania (MAYER-GROSS ${ }^{7}$, COLEMAN ${ }^{2}$, KORNETSKY $^{6}$ e VIDAL e alii ${ }^{11}$ ). 0 dependente de uma determinada droga, vendo-se privado desta por problema financeiro, dificuldade em encontrá-la ou qualquer outro obstáculo, lança mão de qualquer droga para satisfazer sua necessidade surgindo então a politoxicomania.

Com base na literatura especializada e nas próprias observações percebe-se que o farmacodependente apresenta, de modo geral, manifestações de comportamento que evidenciam traços de alterações psíquicas (SANTO-DOMINGO CARRASCO ${ }^{10}$,

\footnotetext{
* Professor Assistente da disciplina Enfermagem Psiquiátrica da EEUSP. Mestre em Enfermagem.

* * Professor Assistente Doutor da disciplina Enfermagem Psiquiátrica da EEUSP.
} 
OLIVENSTEIN ${ }^{8}$ EY et alii ${ }^{1}$ ). Entre os pacientes dependentes de droga, internados para tratamento, observam-se com freqüência manifestações de comportamento características de personalidade psicopática, de oligofrenia, de sintomas neuróticos e psicóticos.

A pessoa com personalidade psicopática consome droga simplesmente por prazer ou movida pela própria caracteristica de seu comportamento — não aceitação dos padrões sociais vigentes e ausência de preocupação pelas conseqüências de seus atos. $\mathrm{O}$ oligofrênico, em geral, é levado à farmacodependência pelo alto grau de sugestibilidade que apresenta; devido a essa característica torna-se facilmente manipulável pelos traficantes, intermediários e outros farmacodependentes que o iniciam no mundo das drogas; torna-se, assim, "inocente útil" porque, além de consumir a droga, passa a obtê-la para os outros. A pessoa que apresenta comportamento decorrente de sintomas neuróticos muitas vezes faz uso de droga para se ver livre da ansiedade, do sentimento de fracasso e impotência, frente às situações de vida que não consegue enfrentar. $O$ individuo que apresenta comportamento decorrente de sintomas psicóticos também pode tornar-se dependente de drogas. A pessoa na fase de mania da psicose maníaco-depressiva pode usar drogas para aumentar ainda mais as sensações de prazer e euforia que experimenta nesta fase da doença. $\mathrm{O}$ paciente com comportamento decorrente de sintomas de esquizofrenia pode passar a fazer uso de drogas para se ver livre da ansiedade provocada pelos sintomas iniciais da doença, ou é levado à droga por aqueles que se aproveitam de seu alheamento, passando então a explorá-lo.

Segundo KAMER \& CAMERON 5 o consumo de droga pode ser experimental, ocasional, sistemático, episódico e acidental.

Os adolescentes e jovens consomem a droga de modo experimental, movidos pela curiosidade; os estudiosos, para observarem os efeitos dela no comportamento humano. Outras pessoas podem fazer uso de drogas de modo ocasional como no caso' do álcool, cujo consumo é aceito socialmente. De modo sistemático, a droga é consumida já pelos farmacodependentes, que a consomem em várias doses ao dia por grandes periodos de tempo. Uma pessoa pode ainda consumir a droga de modo episódio, fazendo uso desta num periodo de tempo que pode variar de horas a semanas seguidas. $\mathrm{O}$ início da dependência da droga pode dar-se de modo acidental; por exemplo, quando, no curso de uma moléstia, recebe tratamento prolongado com drogas que podem levar à dependência.

As drogas mais comumente usadas são: ópio e seus derivados, maconha, cocaína, barbitúricos, anfetaminas, despersonalizantes e álcool, que deve ser objeto de estudo à parte, uma vez que representa o maior problema de nossa sociedade atual.

Segundo SANTO-DOMINGO CARRASCO ${ }^{10}$, para que uma pessoa desenvolva a farmacodependência deve existir a personalidade toxicofílica ou toxicofilia.

KRAMER \& CAMERON ${ }^{4}$ apresentam, em seu manual sobre farmacodependência, os conceitos básicos emitidos pela Organização Mundial da Saúde, que serão apresentados a seguir. Farmacodependência é um estado psíquico, às vezes físico, causado pela interação entre um organismo vivo e uma droga. Caracteriza-se por modificações do comportamento e por outras reações que compreendem sempre um impulso irreprimível ao uso da droga de forma contínua ou periódica para experimentar sensações de prazer e, às vezes, para evitar um mal-estar produzido pela 
privação da mesma. A dependência pode ser acompanhada ou não de tolerância. Tolerância é o estado de adaptação caracterizado pela diminuição das respostas à mesma quantidade de droga ou pela necessidade de uma dose maior para provocar o mesmo efeito. A dependência pode ser física e psíquica. Dependência psíquica é o estado no qual existe uma sensação de satisfação e um impulso psíquico que exige a ministração regular ou contínua de droga para produzir prazer ou para evitar mal-estar. Esta dependência desempenha um papel muito importante nas intoxicações crônicas por drogas, podendo ser, às vezes, a única responsável pela farmacodependência de certos tipos de drogas. Dependência física é o estado de adaptação que se manifesta por meio do aparecimento de transtornos físicos provocados pela interrupção do uso da droga. Estes transtornos caracterizam a síndrome de abstinência. Os sinais e sintomas da síndrome de abstinência são peculiares a cada droga. Ela pode ocorrer quando há supressão brusca no consumo de uma droga que provoca dependência física. Na prática, entretanto, as características comuns a cada droga não são identificadas facilmente porque é raro encontrar-se pessoa que faça uso de uma única droga. A síndrome de abstinência que se encontra descrita na literatura especializada (SANTO-DOMINGO CARRASCO ${ }^{10}$ e KRAMER \& CAMERON ${ }^{4}$ ) é ocasionada pela interrup̧̧ão brusca no consumo do ópio e seus derivados. Os sinais e sintomas mais comumente observados são bocejo, lacrimejamento, sudorese, inquietação, anorexia, tremores, hipertermia, hipertensão arterial, insônia, diarréia, vômito, prostração e, até, a ocorrência de morte.

\section{Problema social provocado pela farmacodependência}

O problema social que a farmacodependência provoca é muito amplo pois envolve o indivíduo, a família e a sociedade como um todo. É um problema de âmbito internacional no qual o fator econômico-financeiro constitui papel predominante. Tendo em vista estes aspectos pode-se concluir que o controle do consumo de drogas que causam dependência torna-se cada vez mais difícil.

Dentre os problemas sociais, a ORGANIZACIÓN MUNDIAL DE LA SALUD $^{\theta}$ destaca perdas econômicas para a família e a sociedade, manifestações de comportamento anti-sociais com vistas a obtenção da droga ou como conseqüência do efeito desta e o aliciamento de novos dependentes.

Outros problemas sociais evidenciam farmacodependência; a prática do homossexualismo que, às vezes, pode ser condição para a obtenção da droga ou conseqüência do uso desta. Problema de igual gravidade que ocorre, ainda, é a prostituição, tanto feminina como masculina. Roubo, homicídio, suicídio, venda de objetos de valor estimativo para a família, roubo de receituário médico são outros problemas conseqüentes ao uso abusivo de drogas. Podem surgir, também, problemas de saúde pública que exijem atuação especial; dentre eles pode-se destacar acidentes automobilísticos e hepatite, infecções e septicemia provocadas por aplicação de injeções parenterais com material não esterilizado. A farmacodependência gera problemas tanto para a própria pessoa como para a sociedade em que vive.

\section{Caracteristicas do comportamento do farmacodependente}

Caracteriza o comportamento de um paciente dependente de droga o fato de todas suas ações visarem a obtenção da mesma. Como conseqüência, toda sua atenção está polarizada para a obtenção da droga. Em decorrência disto, esse paciente 
não cuida de sua aparência, de sua higiene pessoal e não se alimenta adequadamente. Quando hospitalizado procura agrupar-se com outros pacientes que apresentam as mesmas caracteristicas de comportamento; manipula as pessoas da equipe hospilar, visando a obtenção da droga. Apresenta labilidade de humor; pode queixar-se de dor, mal-estar, cansaço e tontura; apresentar lesóes corporais, desde ligeiras equimoses até abcessos e, conseqüentemente hipertermia.

O comportamento do paciente depende de droga decorre de distúrbios nas esferas instintiva (perversão do impulso de nutrição) e na da personalidade (psicopática, psicótica e neurótica). Há outras funções psíquicas que ficam afetadas; mas dependem, basicamente, dos distúrbios das áreas citadas, das drogas usadas e do estado geral do paciente.

\section{Assistência de enfermagem}

Da observação do comportamento de pacientes dependentes de drogas, quando internados em hospital psiquiátrico, pode-se perceber que estes pacientes apresentam problemas característicos. $O$ principal é a própria dependência da droga porque, quando o paciente se vê privado dela, pode experimentar sensações desagradáveis; estas geram ansiedade crescente que podem levá-lo a execução de atos anti-sociais e, inclusive, ao suicídio. Aceitar a internação em hospital psiquiátrico para tratamento é outra barreira para o paciente, porque este não se sente doente e muito menos doente mental. Este fato, somado ao da não aceitação de autoridade, outra característica de comportamento, levam-no à dificuldade no ajustamento às rotinas da unidade de internação. Pode-se acrescentar, ainda, a rejeição sentida pelo paciente ante a não aceitação social de seu comportamento e os problemas decorrentes dos sintomas físicos que dependem das suas condições gerais (insônia, tremores, parestesias, abcessos cutâneos, mal-estar geral, etc.).

Ao cuidar do paciente com comportamento decorrente do uso de drogas, em uma unidade psiquiátrica de internação, a enfermeira enfrenta uma série de problemas. Um dos maiores é a não-aceitação da farmacodependência em si e, principalmente, como entidade clínica devido à sua atitude negativa em relação a ela. Conseguir respeitá-lo como ser humano, sem julgar seu comportamento, e estabelecer limites, sem demonstrar irritação ou agredí-lo, são outros aspectos importantes no cuidado desse paciente. A tentativa de manipulação e de sedução, por parte do paciente, e o envolvimento emocional, que em geral ocorre, podem constituir um obstáculo na assistência de enfermagem. Conseguir evitar que formem grupos com outros pacientes com as mesmas manifestações de comportamento ou com diagnóstico de personalidade psicopática é, também, dificuldade no cuidado de farmacode. pendentes. Outros problemas são: conseguir evitar que provoquem motins, planejem fugas, cometam homicídios, suicídio e que tenham acesso à droga; controlar visitantes e funcionários para evitar que tragam a droga para o paciente, distinguir dentre as queixas somáticas, as reais e as simuladas para obter qualquer medicamento; e levar o farmacodependente de drogas a cuidar de sua higiene e aparência pessoal.

Ao prestar assistência de enfermagem a paciente com comportamento decorrente de dependência de drogas, a enfermeira deve, antes de mais nada, avaliar sua própria atitude e sentimentos em relação a esse paciente; só depois que conseguir desenvolver uma atitude de aceitação genuina desse indivíduo como ser humano, 
apesar de seu comportamento, é que ela conseguirá tornar-se realmente terapêutica em seu relacionamento com o paciente; assim, estará em condições de avaliar objetivamente as suas necessidades, considerando sua personalidade, suas experiências passadas e seu relacionamento com pessoas significativas para ele. Caso a enfermeira não consiga desenvolver atitude de aceitação do paciente, poderá transmitir-lhe a descrença na sua recuperação, reforçando nele o que comumente se ouve dizer: "a pessoa depente de droga é irrecuperável, nada mais há a fazer por ela". A enfermeira deverá, portanto, esforçar-se ao máximo para desenvolver atitude de aceitação em todos aqueles que assistem o paciente.

Para que o dependente de drogas aceite a sua internação em hospital psiquiátrico para tratamento, a atuação terapêutica da enfermeira deverá iniciar-se desde o momento de sua internação. Deverá dizer claramente ao paciente o porquê da hospitalização, da revista rigorosa em seus pertences, da necessidade de seguir as rotinas da unidade e o que se espera dele.

A enfermeira deverá oferecer apoio emocional ao paciente ajudando-o a desenvolver auto-estima, auto-confiança e respeito próprio. Isto lhe trará segurança e conseqüente diminuição do nível de ansiedade.

Quando o paciente tentar manipular a enfermiera para satisfação de seus próprios interesses ela deverá estar atenta para a ocorrência deste fenômeno, limitar o comportamento do mesmo e exigir que esses limites sejam respeitados. Deverá estabelecer limites com tato, mas de modo firme, para não gerar hostilidade, uma vez que essas pessoas têm como característica de comportamento a não-aceitação de autoridade.

O paciente pode, também, tentar envolver emocionalmente a enfermeira, chegando mesmo à tentativa de sedução. A enfermeira não percebendo estar sendo manipulada, poderá ser envolvida emocionalmente e passar a aceitar seu comportamento como adequado. $O$ paciente pode tentar manipular elogiando as qualidades da pessoa que ele está querendo envolver. Às vezes oferece seus préstimos, mostra-se dócil e acata as solicitações desta pessoa. É essencial que a enfermeira compare suas observações e crenças a respeito do paciente com outras pessoas da equipe com formação profissional de mesmo nivel, para validá-las. Caso contrário, ao perceber que foi objeto de manipulação do paciente, poderá reagir de modo não terapêtico, agredindo o paciente e levando todos da equipe a agir emocionalmente como ela.

Evitar que paciente dependente de drogas forme grupo com outros pacientes com o mesmo comportamento, com diagnóstico de personalidade psicopática ou com oligofrenia, e ao mesmo tempo mantê-los ocupados em atividades produtivas, em grupos separados, é outra tarefa da enfermeira. Deve haver vigilância constante e discreta para evitar que planejem fugas, motins e outros atos antisociais.

A enfermeira deve impedir que o paciente tenha acesso à sala de medicamentos da unidade, mantendo-a sempre fechada; e, não deve deixar a bandeja de medicação ao seu alcance. Deve certificar-se de que pacientes com comportamento decorrente de sintomas catatônicos, de depressão e de oligofrenias ingeriram realmente a medicação, porque estes podem não deglutíla e guardá-la para uma pos- 
sível tentativa de suicídio, ou, devido à sugestibilidade, fornecer o medicamento ao paciente dependente de droga.

Não deverá, a enfermeira, mostrar-se decepcionada perante os pacientes que tinham demonstrado firme propósito de regeneração e que voltam ao hospital para tratamento; não deve recebê-los com frases como: "Já de volta?" "De novo aqui?" "Sabia que o senhor iria voltar!". Isto porque o paciente chega à unidade em péssimas condições físicas e psíquicas e com a auto-estima muito diminuída. Um comentário deste tipo iria agravar mais a sua situação.

É indispensável que a enfermeira leve em consideração as queixas do paciente $\mathrm{e}$ as avalie objetivamente, para distinguir os sintomas reais dos simulados. Em geral, ele apresenta estas queixas visando a obtenção de algum medicamento, podendo, às vezes, chegar até à auto-mutilação. A enfermeira deverá estar alerta, também, para perceber, dentre aquelas queixas, os sintomas indicativos da síndrome de abstinência.

Propor situações para o paciente analisar, estimulando gradativamente seu senso de responsabilidade, demonstrando que acredita nele, é outro cuidado a ser prestado pela enfermeira.

A enfermeira não poderá esquecer-se dos aspectos de higiene e alimentação, prestando assistência de acordo com a situação e condições de cada paciente; deverá, também, oferecer assistência de enfermagem específica de acordo com a situação de cada paciente - intoxicação barbitúrica, estado comatoso, desnutrição, etc.

É, ainda, responsabilidade da enfermeira a orientação dos familiares e visitantes do paciente para que não lhe tragam a droga; deverá esclarecê-los sobre a nocividade das drogas e seus efeitos no organismo; e sobre como ajudar na recuperação do paciente (círculo de amigos, atividades profissionais e sociais). Ressaltar ainda a importância do apoio e respeito oferecidos ao paciente.

$\mathrm{Na}$ convalescença a enfermeira deverá analisar junto com o paciente a reestruturação de seu modo de vida, avaliando se suas perspectivas para o futuro são compatíveis com suas reais condições; orientá-lo sobre a importância do controle ambulatorial após a alta; e, orientá-lo sobre os recursos da comunidade.

A enfermeira terá que ensinar todos esses cuidados aos funcionários, discutir, periodicamente, com eles, as dificuldades encontradas e orientá-los sobre o melhor modo de saná-las. Deve levar em consideração que essa assistência está sendo prestada a um paciente que se sente ansioso, rejeitado e irritado pela colocação de limites ao seu comportamento, pela não-aceitação de autoridade e pela falta da droga.

A assistência de enfermagem ao paciente farmacodependente só terá resultado positivo se for desenvolvida por todas as pessoas que prestam assistência ao paciente.

\section{Alguns aspectos profiláticos da farmacodependência}

Ao se tentar fazer a prevenção da farmacodependência todos devem estar atentos para o fato de não despertar a curiosidade sobre os efeitos das drogas, prin- 
cipalmente dos jovens, que estão à procura de novas experiências. Deve-se dar sempre informações completas com bases científicas.

Informações corretas deverão fazer parte de periódicos de grande circulação e de acesso também aos adolescentes.

Os órgãos oficiais devem estabelecer programas de orientação aos professores, às autoridades judiciais e aos líderes da comunidade para que esses elementos possam atuar na prevenção da farmacodependência.

As famílias devem ser alertadas para observar com tato as mudanças de comportamento de seus familiares, principalmente por ocasião das avaliações escolares e quando percebem a falta de objetos de valor material. A imprensa deve evitar publicidade exagerada em torno de ídolos da juventude, quando sabe que fazem uso de drogas. Os poderes governamentais devem limitar a disponibilidade das drogas por meio de fiscalização rigorosa e maior controle na distribuição das amostras grátis feitas pelos laboratórios farmacêuticos.

A população, em geral, deve esforçar-se ao máximo no fomento da criação de centros de interesse sadios para as pessoas em desenvolvimento.

O importante é criar uma consciência coletiva a respeito da nocividade da droga.

STEFANELLI, M. C.; FUKUDA, I. M. K.; ARANTES, E. C. Nursing care of the drug addict patient. Rev. Esc. Enf. USP, São Paulo, 13(2): 127-134, 1979.

The authors describe types of drug addiction, behavior of the drug addict patient and the role of nursing personnel in dealing with them. They also mention some prophylactic measures in the fight off drug addiction.

\section{REFERENGIAS BIBLIOGRAFICAS}

1. EY, $\mathbf{H}$. et alii - El desequilibrio psíquico. In: Barcelona, Toray-Masson, 1978. p. 351, 357.

2. COLEMAN, J. C. - Alcoolismo e o vicio em entorpecentes. In: doa normal e a vida contemporânea. São Paulo, Pioneira, 1973. v. 2, p. 608

3. GREENBLATT, D. J. \& SHADER, R. I. - Dependência de barbitúricos e sedativo-hepnóticos: tratamentó. In: SHADER, R. I. Manual de terapêutica psiquiátrica-psicofarmacologia prática e psiquiátrica. Rio de Janeiro, Athenell, 1978. p. 171.

4. KRAMER, J. F. \& CAMERON, D. C. - Conceptos básicos y terminología. In:

Manual sobre dependencia de las drogas. Ginebra. OMS, 1975. cap. 1, p. 13-7, 42.

5. Tipos de consumo. In: - Manual sobre dependencia de las drogas. Ginebra, OMS, 1975. cap. 2, p. 23-4.

6 KORNETSKY, C. - The nonmedical use of drugs. In: affecting behavior. New York, John Wiley \& Sons. 1976. p. 186.

7. MAYER-GROSS, W. et alii - Alcoolismo, adição a drogas e outras intoxicações. In: Psiquiatria clínica. São Paulo, Mestre Jou, 1972. p. 434.

8. OLIVENSTEIN, C. L. - Algo ha pasado. In: - Las drogas (drogados e toxicomanos). Madrid, Studium, 1971. p. 7.

9. ORGANIZACION MUNDIAL DE LA SALUD - Evaluación de los problemas sociales y de salud pú. blica. In: \} \text { Comité de expertos de la OMS en farmacodependencia. Ginebra, } OMS, 1978. (Serie de Informes Técnicos, 618).

10. SANTO-DOMINGO CARRASCO, J. - Alcohólicos y toxicómanos. In: - Elementos de psiquiatría y asistencia psiquíatrica. Barcelona, Científico-Médica, 1968. cap. 18, p. 221-2.

11. VIDAL, G. et alii. - Farmacodependência. In: nos Aires, El Ateneo, 1977. p. 232, 233.

12. WARNER, J. - The main line to Europe. Nurs. Mirror, London, 148 (5): 13-6, Feb. 1, 1979.

\section{BIBLIOGRAFia CONSUltada}

ARRUDA, A. et alii - A droga: quem toma, o que toma, porque toma. Rio de Janeiro, Civilização Brasileira, 1966.

$\mathbf{E Y}, \mathbf{H}$. et alii - El desequilibrio psíquico. In: Tratado de psiquiatría. 8. ed. Barcelona, Toray-Masson, 1978 
GREEN, A. I. et alil - O vício da herolna e da metadona: conduta aguda e crónica. In: SHADER, R. I. Manual de terapêutica psiquiátrica-psicofarmacologia prática e psiquiátrica. Rio de Janeiro, Atheneu, 1978. p. 179-85.

GREENBLATT, D. J. \& SHADER, R. I. - Más viagens: tipo particular de efeito psicodisléptico. In: SHADER, R. I. Manual de terapêtutica psiquiátrica-psicofarmacologia prática e psiquíátrica. Rio de Janeiro, Atheneu, 1978. p. 163.70.

Dependéncia de barbitúricos e sedativo-hipnótico: tratamento. In: SHADER, $R$. I. Manual de terapêutica psiquiátrica-psicofarmacologia prática e psiquiátrica. Rio de Janeiro, Atheneu, 1978. p. $171-7$.

GREEN, A. I. et alii - Superdosagem psicofarmacológica. In: SHADER, R. I. Manual de terapêutica psiquiátrica-psicofarmacologia prática e pslquiátrica. Rio de Janeiro, Atheneu, 1978. p. 211-39.

HOFLING, $C . K$. et alii - Transtornos de la personalidad. In: 2. ed. México, Interamericana, 1967. p. 297-322.

KALKMAN, M. E. - Nursing care in the personality disorders. In: Psychiatric nursing. 3. ed. New York, McGraw Hill, 1958. p. 148-77.

KRAMER, J. F. \& CAMERON, D. C. - Manual sobre dependência de las drogas. Ginebra. Organización Mundial de la Salud, 1975.

LOURIA, D. B. - The drug scene. London, Gorgi, 1970.

MANFREDA, M. L. \& KRAMPITZ, S. D. - Drug dependency: nursing care. In: Psychiatric nursing. 10. ed. Philadelphia, F. A. Davis, 1977. cap. 28, p. 365-73.

MATHENEY, R. V. \& TOPALIS, M. - Toxicomania, la enfermera y la comunidad. In: Enfermería psiquiátrica. 5. ed. México, Interamericana, 1971.

MERENESS, D. - Enfermos cuya conducta esta clasificada como transtornos de la personalidad. In: 1973. p. $224-57$

OLIVENSTEIN, C. - Las drogas - drogados y toxicomanos. Madrid, Studium, 1971.

VIDAL, G. - Farmacodependencia. In: - Enciclopedia de psiquiatria. Buenos Aires, El Ateneo, 1977. p. 232-8.

WURMSER, L. - Transtornos de personalid y dependencia de drogas. In: LION, J. R. Transtornos de personalidad. Barcelona, Salvat, 1978. p. 126-57. 